\title{
Introducing the Society for Back Pain Research
}

\author{
Alison H. McGregor · John O’Dowd
}

Received: 2 March 2012/Published online: 20 March 2012

(C) Springer-Verlag 2012

The Society for Back Pain Research is a unique multidisciplinary society that has recently celebrated its 40th year. It was formed to promote the study of all clinical and scientific aspects of spinal pain, including the neck, and to encourage research into its causes, treatment and prevention, and is one of the few successful multidisciplinary societies having over 200 members from a wide range of disciplines including clinicians, such as orthopaedic surgeons, rheumatologists, neurologists and general practitioners, basic scientists including biochemists, bio-engineers, anatomists and epidemiologists, as well as various other practitioners including physiotherapists, osteopaths and chiropractors.

Scientific meetings are held yearly and non-members are welcome to attend. Papers on various aspects of back pain research are presented and discussed and the best abstracts in each year are published. Symposia are devoted to specific topics of particular current relevance. Every effort is made to keep the costs of the meetings to a minimum. We regularly hold joint meetings with our European partner societies, which are always well attended and supported.

Membership of the society is open to any clinical or scientific worker who has an active interest in back pain research and who wishes to further the aims of the society. Many members go on to be involved in a range of other spinal activities including leading roles in NICE guidelines and Cochrane reviews. Like BASS, we are very much involved and supportive of the UKSSB and its initiatives.

Further details are available on our website http://www. sbpr.info/.

We are delighted to have been invited to participate in and contribute to this supplement. It illustrates the breadth of current low back pain research, ranging from basic cell biology to complex surgical techniques, and emphasises the importance of basic clinical assessment and measurement. Whilst complex multicentre randomised controlled trials remain the gold standard, and we must support and encourage them, they are increasingly expensive and difficult to do, and it is essential that individual scientists and clinicians continue to study the scientific building blocks of our discipline. We believe that this supplement illustrates how effective this activity can be, and we hope that you will be stimulated to go away and look at clinical and basic science problems with a fresh mind.

Conflict of interest None.

\footnotetext{
A. H. McGregor ( $\square$ )

Department of Surgery and Cancer, Faculty of Medicine, Imperial College London, Charing Cross Hospital, London W6 8RF, UK

e-mail: a.mcgregor@imperial.ac.uk

J. O’Dowd

RealHealth Institute, 17 Red Lion Square,

London WC1R 4QH, UK

e-mail: johnodowd@btinternet.com
} 